\title{
The Novel as a Source for the Historian?
}

\author{
By Reino Kero \\ University of Turku
}

Kristian Hvidt has probably written his paper to generate discussion. A little exaggeration is required on the part of the generator; thus I consider some of Hvidt's assertions to be intentionally provocative. Nevertheless, I think that Hvidt's paper ought to be taken at face value.

In his own research, Hvidt has specialized in the history of immigration, and he continues that familiar interest in this paper. In preparing his dissertation, Hvidt emphasized the use of "hard" sources, e.g., quantitative materials and statistics. The "soft" sources of history - novels, short stories and letters - were not given much credence at that time. Now, however, Hvidt considers something missing in historical research which utilizes only "hard" sources. Still, Hvidt maintains that it is rarely possible to use novels, short stories and similar sources.

In addition to discussing the possible uses of various sources, Hvidt also attempts to separate history from other social sciences. In his discussion, he comes to the conclusion that there is a hazy distinction between the two. Conversely, the line between historical research and literary scholarship can, in his opinion, be clearly drawn.

Dorothy Burton Skårdal, who has used the literary efforts of immigrants in her research, has an entirely different view of the use of such source materials as novels. As far as she is concerned, the novel and the short story are as useful as sources considered to be "hard."

Before I examine the views of Hvidt and Burton Skårdal, I will mention parenthetically that, in my own background, I have used the computer in three research projects, while in others I have familiarized myself with the use of newspapers, letters and even novels.

While examining the papers of Hvidt and Burton Skårdal, I decided to seek out a typical Finnish American immigrant novel and see what kind of source it would be for the study of Finnish immigration to America. What impression of Finnish American immigration does 
a typical Finnish American novel give? How correct or incorrect is this impression when compared to the impression of immigration given by other sources?

Maansa hylkäämiä (Outcasts of their Country. Fitchburg, Mass., [1928]), a novel written in the 1920 's by Moses Hahl, is a very typical Finnish American novel. It describes how the hero left Finland and what he experienced in America. The viewpoint is leftist, as in most Finnish American novels. 'The writer himself left Finland in 1903, or at the same time as the immigrants he depicts. Therefore, there is reason to believe that he knew his immigrant world very well.

Hahl undoubtedly strove for artistry in his writing. Yet, he did not write only for his own pleasure or for the entertainment of his readers. He had a clear purpose in his writing: he wanted to write in such a way that the reader would feel antipathy toward Finland, the economic life of the United States and the Finnish American churches. Furthermore, Hahl did not write with the unlimited freedom of the artist, but rather attempted to find a "truth" that readers in the Finnish American immigrant society could accept, as he sought to persuade them.

In the preface to the book, he wrote:

The characters in this book were not created in a vacuum, nor are the events in their lives and their personal characteristics imaginary. The characters are real people ... The experiences attributed to the characters in this book have actually happened. Naturally the characters and their individual qualies are, in a f instances, somewhat instances, somcwhat embcllished, so that they might be obvious, but their characteristics and experiences have not been exaggerated at the cxpense of truth

Hahl seems to have taken the stand that his story had to bear a certain rclationship to the information his readers had about Finland and America: the story had to correspond to the cxperiences and the information of the potential readership.

Although Hahl's conscious or subconscious premise was that he was restricted by the information of his potential readership, he was still left with considerable latitude. It is true that the readership had to be convinced that all this could have really happened, but the credibility of the circumstances was of lesser importance. Thus, Hahl's Finland is inhabited solely by ruthless aristocrats and tcnant farmers driven from their homes, or otherwise oppressed and unsuccessful people. For their part, the Finnish Americans are, almost without exception, tramps who are exploited and deceived by capitalists and who gather occasionally in taverns to drown themselves in drink. The Finnish American clergy, in turn, are immoral stooges of entrepreneurs.

If Hahl's book were the only source of information on Finnish Americans, its descriptions would provide very reliable information on many facets of immigrant life. Through a conventional review of sources, it would be possible to establish the extent to which the writer's own purposes have served to alter the general image that has been created of the immigrant. As a vestige of the past, this novel powerfully bears witness to the immigrant world view, specifically, Hahl's world view.

Acquaintance with Hahl's novel convinces me that the novel is, in practice, a very useful tool for the student of immigrant history, and undoubtedly, of many other areas of history as well. The degree of utility depends on the historical subject under scrutiny. The past itself is only a construct built to explain the "traces" left by certain people. The novel is, of course, a trace of the past in the same way as that most-frequentlyused "hard" source in immigrant history, the passenger list. The existence of Hahl's novel presumes the existence of a certain world view, and it is a reliable source for the student of that world view. Becoming acquainted with Hahl's novel makes a reader realize that there is sometimes little difference between a novel and a memoir. Thus, if the historian is denied the right to use the novel, then he should also be denied the memoir as well.

While maintaining that the novel and the short story cannot be sources of information for a historian, Hvidt also attempts to draw a line between historical research and literary scholarship. This line, according to him, is "clear and sharp." It is a "line between fact and fiction, a border which ordinary historians cannot pass, whereas students in literature must pass it when they analyse fiction." Nevertheless, the line between history and literary scholarship seems somewhat unclear to Hvidt himself. He disapproves of the literary scholars' excessive eagerness to study history: "Scholars of literature go too far into the historical fields." On the other hand, Hvidt appears to insist that historians read novels and short stories so as to have a better understanding of the past. Wouldn't this requirement lead to a blurring of historical research and literary scholarship, and wouldn't the novel thus become source material for historical research?

Historical research has been variously defined over time. Most definitions are, nonetheless, based on the assumption that history is a science and not a partial art, as Burton Skardal states. If the use of words makes science a partial art, as Burton Skårdal thinks, could 
not almost all sciences be classified as half-art? The object of historical research is clear. It is the past. But if this object is clear, it is, on the other hand, very extensive. It should be added that there are other sciences whose object is also the past. Historical research has its own. methods, but other sciences can use the methods developed in the sphere of historical research. Conversely, historical research uses methods developed by scholars in other fields. Ultimately, it may be that the borders of historical research are no more unclear than for most sciences. And although it is very natural for historical research to attempt to be an independent, separate branch of scholarship, it is probably inappropriate to draw lines which would be, in Hvidt's words, "sharp and clear." Such lines are mechanical and contrived. 